\title{
SPATIAL AND SEASONAL PATTERNS OF PRECIPITATION IN GREECE: THE TERRAIN SEGMENTATION APPROACH
}

\author{
DEMERTZI K. ${ }^{1}$ \\ PAPAMICHAIL D. ${ }^{1}$ \\ ASCHONITIS V., \\ MILIARESIS G. ${ }^{3}$
}

\author{
${ }^{1}$ Department of Hydraulics, Soil Science and Agricultural Engineering \\ Aristotle University of Thessaloniki, Greece \\ ${ }^{2}$ Department of Life Sciences and Biotechnology \\ University of Ferrara, Italy \\ ${ }^{3}$ Environmental Conservation \& Management \\ Faculty of Pure and Applied Sciences \\ Open University of Cyprus, Cyprus
}

Received: 06/07/2014

Accepted: 24/09/2014

Available online: 05/12/2014

\section{ABSTRACT}

The aim of the study is to investigate the spatial and seasonal variation of precipitation in Greece using multi-temporal data analysis techniques. Mean monthly precipitation grids at $\sim 1 \mathrm{~km}^{2}$ resolution for the period 1950-2000 were used in the analysis. Cross correlation quantified spatio-temporal patterns which are summarized as follows a) the absolute correlations of precipitation versus elevation and longitude are minimized during the winter period, b) the latitude dependency of precipitation presents a seasonal shift where winter precipitation tends to be higher in northern Greece, while summer precipitation tends to be higher in southern Greece. Principal components analysis indicated that the first two components account for the $92.8 \%$ of variance in the spatio-temporal variability of precipitation. Cluster analysis segmented the terrain to 27 regions with distinct seasonal variability of precipitation. The majority of irrigated agricultural land (plains of Macedonia, Thessaly and Thrace) belong to clusters which present the lowest values of annual precipitation ( $<600 \mathrm{~mm}_{\text {year }}{ }^{-1}$ ). The derivation of precipitation signatures for each region of Greece using the proposed terrain segmentation approach can support environmental decision and agricultural planning at a regional (country) scale in relation to water resources management.

Keywords: imagery correlations, principal components, terrain segmentation, environmental decision support, agricultural planning.

\section{Introduction}

Precipitation is one of the most important hydroclimatic parameters because it regulates the available water for evaporation from soil, transpiration by plants, surface runoff, groundwater recharge and soil moisture increment. These elements are essential for the development of water management planning for agricultural, domestic and industrial-energy uses (McMahon et al., 2011; Thenkabail et al., 2012; Demertzi et al., 2014; Kaffas and Hrissanthou, 2014). 
The intra-annual and spatial variability of precipitation for different time scales and sub-regions of Greece have been analyzed using different techniques of multivariate data analysis (Papamichail and Metaxa, 1996; Metaxas et al., 1999; Fotiadi et al., 1999; Loukas et al., 2001; Bartzokas et al., 2003; Oikonomou et al., 2008; Stathis and Myronidis, 2009; Stathis and Mavromatis, 2009; Nastos and Zerefos, 2010; Feidas et al., 2013). On the other hand, a major drawback of such analyses is that a terrain segmentation framework according to the hydroclimatic parameter under study (i.e. precipitation) has not yet been defined for Greece. Thus, sub-regions with distinct seasonal precipitation variability can be defined with the implementation of multitemporal data analysis techniques.

Representative examples of terrain segmentation techniques have been applied using multi-temporal data of land surface temperature (LST) in an attempt to define sub-regions with different seasonal LST variability, to assess its sensitivity to climatic change and to support environmental analysis (Maeda and Hurskainen, 2014; Miliaresis, 2009; Miliaresis and Partsinevelos, 2010; Miliaresis and Tsatsaris, 2010). In addition Miliaresis $(2013,2014)$ proposed a method for standardizing multi-temporal LST imagery in order to reveal and describe thermal anomalies using elevation, latitude and longitude dependencies.

The available global grids of monthly precipitation data (Hijmans et al., 2005; Sheffield et al., 2006 etc) stimulate the need for the implementation of terrain segmentation techniques to the hydroclimatic parameters analysis. Such a research effort can quantify the environmental suitability of a certain terrain sub-region according to its distinct seasonal precipitation variability.

The aim of the study is to propose a terrain segmentation framework for the analysis and interpretation of multi-temporal precipitation data. Towards this end, the seasonal variability of precipitation in Greece for the period 1950-2000 will be captured, while the terrain will be segmented to regions with different monthly precipitation signatures. This effort will be valuable in assisting environmental decision support and agricultural planning in relation to water resources management.

\section{Data and methods}

\subsection{Study area and Data}

The study area corresponds to Greece (South-East Europe) which is confined between the 34 and 42 parallel North, with a meridional extent from 19 to 28 East and a total area of $\sim 14 \times 10^{4} \mathrm{~km}^{2}$. The area is described by Mediterranean climate: mild-cold and rainy winters, relatively warm and dry summers and, generally, extended periods of sunshine throughout most of the year (Hellenic National Meteorological Service, http://www.hnms.gr/hnms/english/climatology/climatology_html). The analysis was based on gridded climatic data which were obtained from the database of Hijmans et al., (2005). The data provide mean monthly values of precipitation at 30 arc-sec spatial resolution $(\sim 1 \times 1 \mathrm{~km})$ of the period 1950-2000 (http://www.worldclim.org/). The database also includes a revised version of the GTOPO30 DEM at 30 arcsec spatial resolution.

\subsection{Methods}

A set of three statistical methods such as correlation, principal components and k-means cluster analysis were combined in GIS environment for imagery analysis. Correlation analysis and principal component analysis (PCA) were used in order to reveal the temporal and spatial patterns of precipitation. PCA is a linear transformation technique that produces a set of images known as PCAs that are uncorrelated with each other while they are ordered in terms of the amount of variance they explain from the original image set (Maaten and Hinton, 2008). PCAs are computed from the linear combination of eigenvectors and the corresponding pixel values of the initial images (Mather, 2004). PCA has traditionally been used in remote sensing as a means of data compaction since it is common to find that the first 2 or 3 components are able 
to explain the majority of the variability in data values, while later components tend to be dominated by noise effects. The rejection of these later components reduces the volume of data with no appreciable loss of information (Siljestrom et al., 1997). Standardized principal components analysis (Eastman and Fulk, 1993) is applied (data per month is centered with mean 0.0 and standard deviation 1.0) and so each image is not weighed according to its variance.

K-means cluster analysis was used to partition the multi-temporal (12-dimensional) imagery of precipitation into $\mathrm{K}$ exclusive clusters. It begins by initializing cluster centroids, then assigns each pixel to the cluster whose centroid is nearest, updates the cluster centroids, then repeats the process until the stopping criteria are satisfied (Mather, 2004). The analysis uses Euclidian distance for calculating the distances between pixels and cluster centroids. The underlying idea of cluster analysis is that the cluster centroids represent the mean expression of the derived clusters. Thus, clustering of the multi-temporal data sets is expected to define groups of pixels with a rather common centroid curve that expresses their average monthly variability (Miliaresis, 2009). Elevation, latitude and longitude statistics per cluster are computed in order to assist interpretation. Finally the clusters are interpreted according to their centroid and their spatial arrangement (Miliaresis, 2014). In the current implementation of the method, small clusters with area extent (occurrence) less than $0.001 \%$ were eliminated by merging them with larger clusters which are closest to their centroids, while the stopping criterion was defined as the percentage of the migrating pixels during a specific iteration (if it was less than $0.001 \%$ of the entire number of image pixels, the clustering was terminated). The maximum number of clusters is defined by a trial and error procedure while the maximum number of iterations is set equal to 300 .
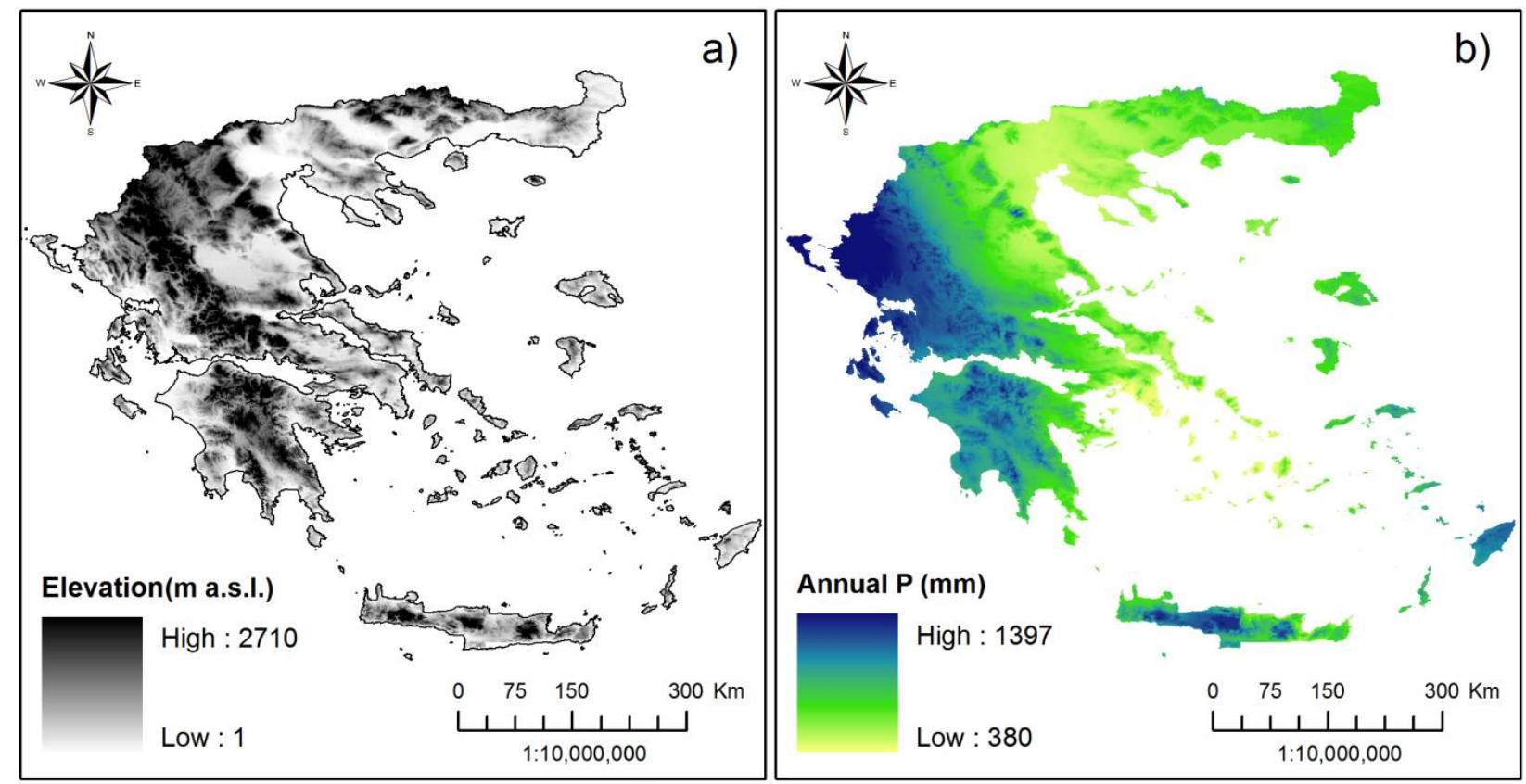

Figure 1. Maps of a) elevation $H$ (meters above sea level), b) mean annual precipitation $P\left(\mathrm{~mm}\right.$ year $\left.^{-1}\right)$ for the period 1950-2000. 


\section{Results and Discussion}

\subsection{Spatial variation of annual precipitation}

The 30 arc-sec resolution maps of elevation $H$ and mean annual precipitation $P$ are given in Figures 1 a and $1 b$, while their frequency distributions are given in Figures $2 a$ and $b$. The precipitation map (Figure 1b) indicates that the highest annual $P$ values are observed in western Greece due to the strong effect of the Pindos mountain range which constitutes a physical obstacle in the movement of vapour masses originated from the southern Alpine system of northern Italy. Apart from the high elevation regions (above $1000 \mathrm{~m}$ ) in western Greece, other regions with high precipitation are observed in Crete and Rhodes islands located in Southern Greece where in the first case the White, Psiloritis and Dikti mountains (in Grete) and in the second case the Babadag, Uyluk and Bey mountains (western Taurus mountains range in Turkey near Rhodes) block the incoming vapour masses from the Libyan Sea leading to precipitation increase. The mean annual value of precipitation over Greece was estimated at $699 \mathrm{~mm}$.
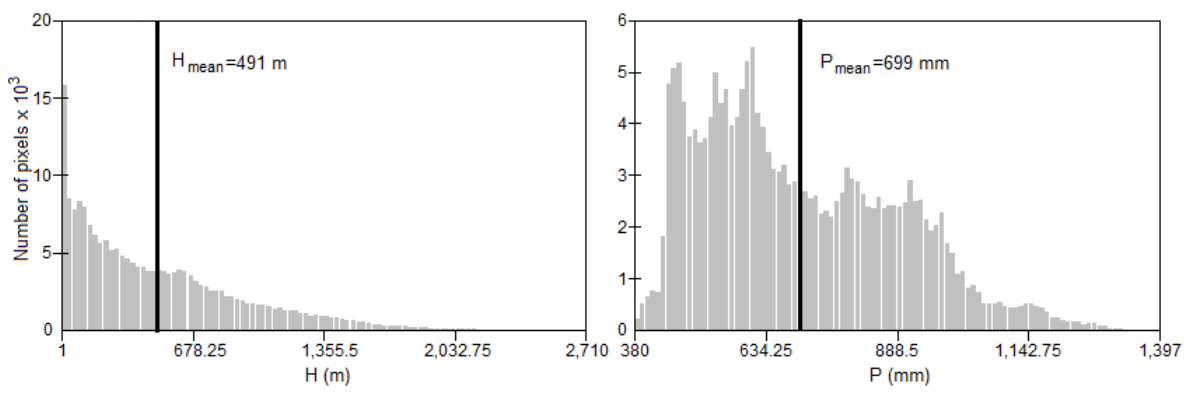

Figure 2. Frequency analysis of the spatial variation of a) elevation $H$, b) mean annual precipitation $P$ for the period 1950-2000.

\subsection{Spatial and seasonal variation of monthly precipitation}

The correlation matrix of the mean monthly precipitation $P$ versus elevation $H$, latitude $L a t$ and longitude Lon is quantified in Table 2. Figure 3 indicates a positive correlation between $P$ and $H$ where the effects of elevation are minimized during winter. The correlation between $P$ and Lat is positive during the warm-dry season and negative during the cold-wet season (October-March) (Figure 3) indicating a seasonal shift of the system. Thus, $P$ during winter tends to be higher in northern Greece while during summer tends to be higher in southern Greece. The correlation between $P$ and Lon is always negative indicating a tendency for higher $P$ in western Greece while its effects are minimized during winter (Figure 3 ).

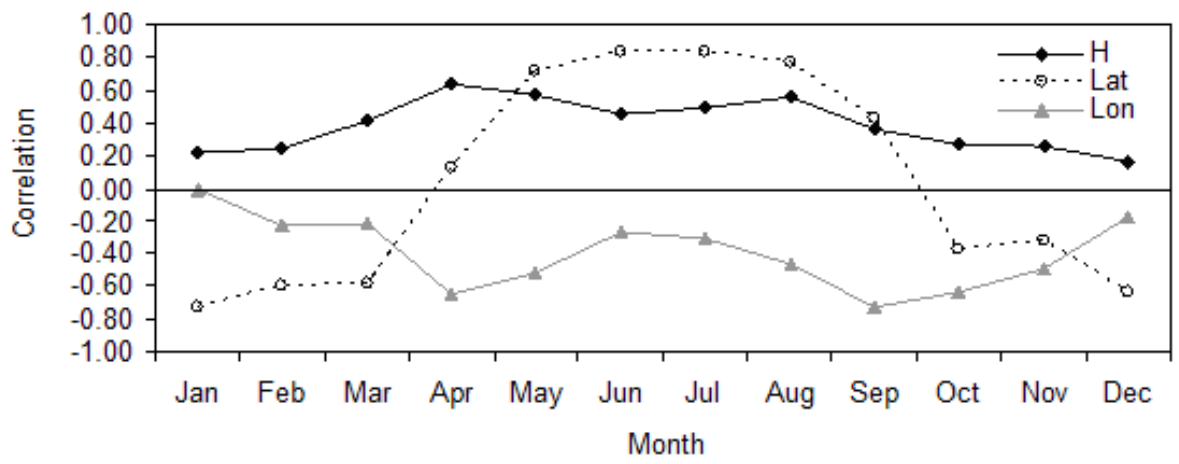

Figure 3. Correlation of mean monthly $P$ versus Lat, Lon and $H$. 
Table 2. Cross correlation matrix between $H$, Lat, Lon and the multi-temporal monthly $P$ images.

\begin{tabular}{|c|c|c|c|c|c|c|c|c|c|c|c|c|c|c|c|}
\hline & $\mathrm{H}$ & Lat & Lon & Jan & Feb & Mar & Apr & May & Jun & Jul & Aug & Sep & Oct & Nov & Dec \\
\hline $\mathrm{H}$ & 1 & & & & & & & & & & & & & & \\
\hline Lat & 0.03 & 1 & & & & & & & & & & & & & \\
\hline Lon & -0.30 & -0.14 & 1 & & & & & & & & & & & & \\
\hline Jan & 0.22 & -0.72 & 0.00 & 1 & & & & & & & & & & & \\
\hline Feb & 0.24 & -0.60 & -0.23 & 0.93 & 1 & & & & & & & & & & \\
\hline Mar & 0.41 & -0.58 & -0.21 & 0.93 & 0.96 & 1 & & & & & & & & & \\
\hline Apr & 0.64 & 0.12 & -0.65 & 0.39 & 0.58 & 0.63 & 1 & & & & & & & & \\
\hline May & 0.57 & 0.71 & -0.51 & -0.29 & -0.14 & -0.03 & 0.67 & 1 & & & & & & & \\
\hline Jun & 0.45 & 0.83 & -0.26 & -0.49 & -0.37 & -0.26 & 0.45 & 0.90 & 1 & & & & & & \\
\hline Jul & 0.49 & 0.83 & -0.31 & -0.52 & -0.42 & -0.30 & 0.41 & 0.93 & 0.96 & 1 & & & & & \\
\hline Aug & 0.55 & 0.76 & -0.46 & -0.40 & -0.27 & -0.16 & 0.54 & 0.96 & 0.89 & 0.95 & 1 & & & & \\
\hline Sep & 0.36 & 0.42 & -0.73 & 0.12 & 0.35 & 0.35 & 0.85 & 0.76 & 0.54 & 0.53 & 0.67 & 1 & & & \\
\hline Oct & 0.26 & -0.37 & -0.64 & 0.71 & 0.83 & 0.82 & 0.75 & 0.15 & -0.14 & -0.16 & 0.02 & 0.66 & 1 & & \\
\hline Nov & 0.25 & -0.32 & -0.49 & 0.76 & 0.87 & 0.81 & 0.70 & 0.09 & -0.18 & -0.19 & 0.00 & 0.62 & 0.92 & 1 & \\
\hline Dec & 0.17 & -0.63 & -0.17 & 0.96 & 0.96 & 0.92 & 0.50 & -0.22 & -0.45 & -0.50 & -0.35 & 0.27 & 0.81 & 0.88 & 1 \\
\hline
\end{tabular}

In order to further interpret the monthly inter-correlations observed in Table 2, principal components analysis (PCA) was implemented and the corresponding eigenvalues and eigenvectors are presented in Table 3. According to the eigenvalues (Table 3), the first two principal components (PC-1 and PC-2) account for the $92.8 \%$ of the total variance observed in the 12 monthly $P$ images. The PC-1 map (Figure $4 a$ ) is composed by linear combinations of monthly $P$ images that amplify the difference between the periods of May-August (negative signs) versus October-April (positive signs) (Table 3). The PC-1 is spatially maximised in the western and south-eastern Greece. For PC-2, the linear combinations of monthly $P$ images amplify the difference between the periods of October-March and April-September. The difference between these two periods is spatially maximised in the north-western Greece and in the mountainous regions of Rhodope while it is minimized in the lowland regions of southern Greece and in the islands of Aegean sea.

Table 3. Eigenvalues and eigenvectors for the PCs of the multi-temporal $P$ monthly images.

\begin{tabular}{ccccccccccccc}
\hline$P$ & & \multicolumn{10}{c}{ Principal Components (PCs) } \\
\hline Eigenvectors & 1 & 2 & 3 & 4 & 5 & 6 & 7 & 8 & 9 & 10 & 11 & 12 \\
\hline Jan & 0.38 & -0.07 & -0.41 & 0.28 & 0.03 & -0.26 & 0.02 & -0.33 & -0.03 & 0.12 & 0.51 & -0.40 \\
\hline Feb & 0.39 & 0.01 & -0.16 & -0.12 & -0.11 & 0.20 & -0.44 & 0.33 & -0.67 & 0.06 & -0.05 & 0.01 \\
\hline Mar & 0.38 & 0.05 & -0.41 & -0.13 & 0.36 & -0.15 & -0.20 & 0.28 & 0.51 & -0.26 & -0.22 & 0.16 \\
\hline Apr & 0.23 & 0.36 & -0.06 & -0.46 & -0.06 & 0.60 & 0.31 & -0.06 & 0.16 & 0.01 & 0.34 & -0.03 \\
\hline May & -0.07 & 0.44 & -0.12 & 0.03 & 0.14 & 0.08 & -0.11 & -0.56 & -0.22 & -0.42 & -0.40 & -0.22 \\
\hline Jun & -0.17 & 0.39 & -0.28 & -0.26 & -0.51 & -0.41 & 0.12 & 0.24 & 0.06 & 0.21 & -0.20 & -0.29 \\
\hline Jul & -0.18 & 0.39 & -0.22 & 0.22 & 0.01 & -0.21 & 0.18 & 0.12 & -0.25 & -0.26 & 0.37 & 0.60 \\
\hline Aug & -0.12 & 0.42 & -0.06 & 0.46 & 0.38 & 0.26 & -0.03 & 0.21 & 0.06 & 0.56 & -0.12 & -0.11 \\
\hline Sep & 0.14 & 0.39 & 0.48 & -0.04 & -0.14 & -0.20 & -0.60 & -0.15 & 0.25 & 0.08 & 0.27 & 0.10 \\
\hline Oct & 0.35 & 0.15 & 0.39 & -0.26 & 0.43 & -0.43 & 0.41 & 0.01 & -0.27 & 0.15 & -0.10 & -0.01 \\
\hline Nov & 0.36 & 0.13 & 0.32 & 0.50 & -0.31 & 0.09 & 0.25 & 0.32 & 0.09 & -0.40 & -0.09 & -0.23 \\
\hline Dec & 0.39 & -0.03 & -0.10 & 0.17 & -0.35 & 0.04 & 0.15 & -0.39 & 0.08 & 0.35 & -0.36 & 0.50 \\
\hline Eigenvalues & 6.26 & 4.88 & 0.44 & 0.14 & 0.10 & 0.07 & 0.05 & 0.04 & 0.01 & 0.01 & 0.01 & 0.00 \\
\hline Variance \% & 52.13 & 40.66 & 3.63 & 1.17 & 0.84 & 0.56 & 0.46 & 0.30 & 0.11 & 0.07 & 0.06 & 0.02 \\
\hline
\end{tabular}



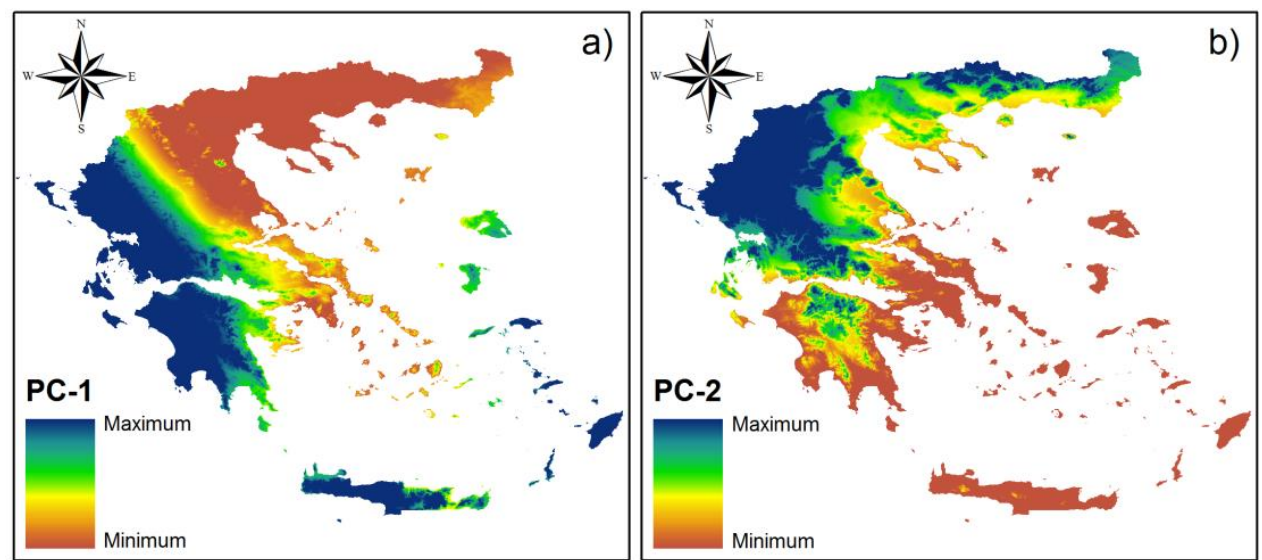

Figure 4. The first two principal components a) PC-1 and

b) PC-2, that account for the $92.8 \%$ of the $P$ variance according to Table 3 .

\subsection{Terrain segmentation based on the spatial and seasonal variation of monthly precipitation}

Cluster analysis provided 27 precipitation clusters where their spatial distribution is given in Figure 5 . Their centroids (latitude, longitude), their percent area extent, mean elevation and the variation of monthly precipitation are given in Table 4. Considering the whole Greece, $P$ is minimized during August and maximized during December, while the $27 \%$ of precipitation is observed during April to September (warmdry period) and the $73 \%$ during the October to March (cold-wet period) (Table 4). Clusters which present significant deviations from the aforementioned general trends or other particular characteristics are the following:

- Cluster 2 (with the greatest area extent) presents a) the lowest value of annual precipitation and b) the highest percentage of precipitation (41.6\%) during the April-September period.

- Cluster 2 together with Cluster 1 and 5 cover approximately 39\% of Greece and present the lowest values of annual precipitation $\left(<600 \mathrm{~mm}_{\text {year }}{ }^{-1}\right)$. It is indicative that these clusters include the plains of Macedonia, Thessaly and Thrace which host the majority of irrigated agricultural land in Greece.

- Cluster 24 (Rhodes island) presents $\alpha$ ) 25\% higher annual precipitation from the mean precipitation in Greece and $b$ ) the lowest percentage of precipitation (8\%) during the April-September period.

- Clusters 10,11, 12, 13 and 20 (north-western Greece) are of particular interest because they present the highest values of annual precipitation exceeding $1000 \mathrm{~m}_{\text {year }}{ }^{-1}$.

- Clusters $3,4,6,7,9,18,22$ and 27 cover the regions of the highest elevation (>900 $\mathrm{m}$ ) providing significant information about the precipitation patterns in the mountainous areas.

- Clusters 1 and 3 are of particular interest because they present high geographical dispersion. 


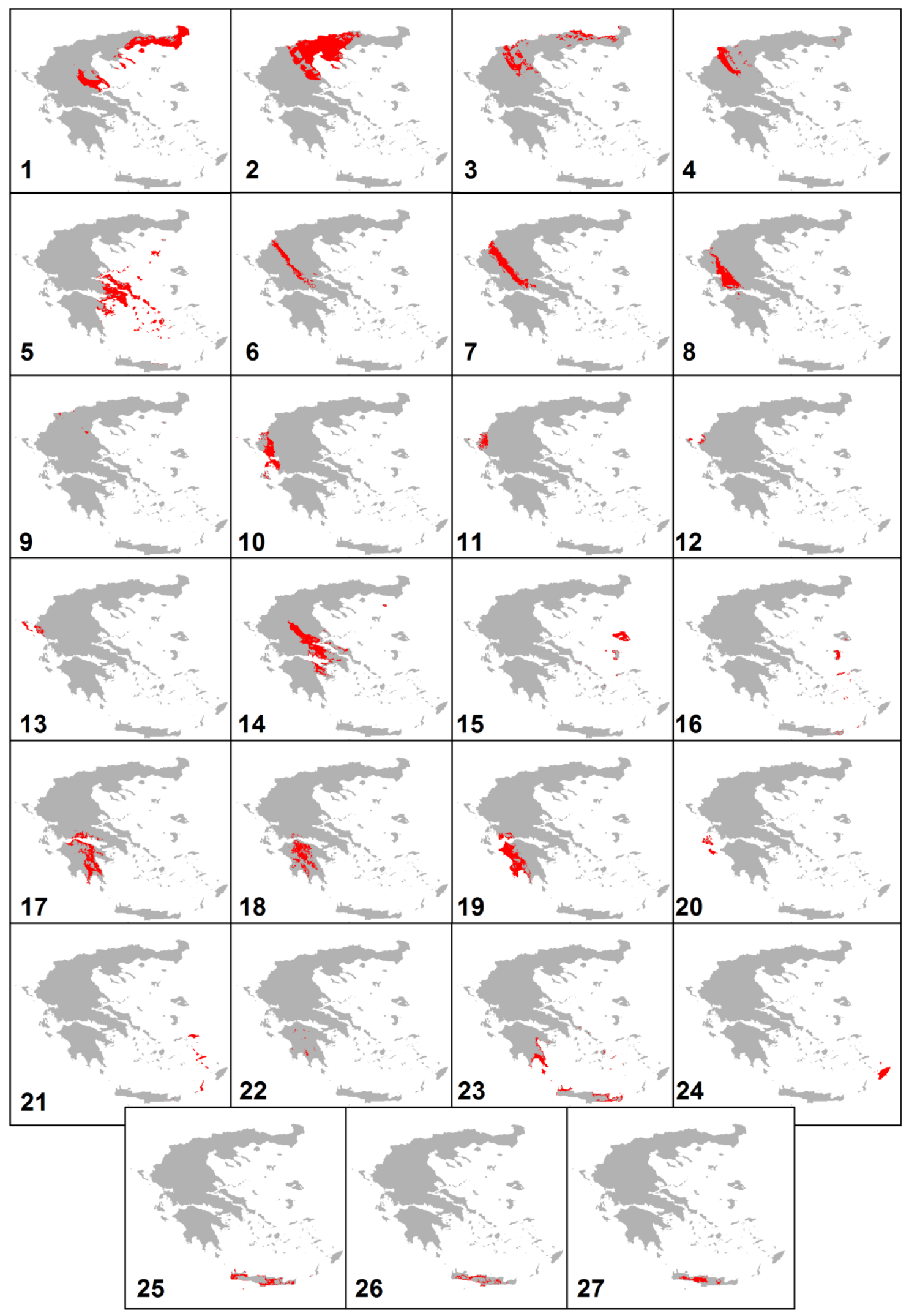

Figure 5. The spatial distribution of the 27 precipitation clusters. 
Table 4. Centroids coordinates, percent area extent, mean elevation $H$, monthly and annual precipitation $P$ of each cluster.

\begin{tabular}{|c|c|c|c|c|c|c|c|c|c|c|c|c|c|c|c|c|c|}
\hline \multirow{2}{*}{ Cluster } & \multicolumn{2}{|c|}{ Centroid } & \multirow{2}{*}{$\begin{array}{c}\text { Area } \\
\%\end{array}$} & \multirow{2}{*}{$\begin{array}{c}H \\
(\mathrm{~m})\end{array}$} & \multicolumn{13}{|c|}{$P(\mathrm{~mm})$} \\
\hline & Lat & Lon & & & Jan & Feb & Mar & Apr & May & Jun & Jul & Aug & Sep & Oct & Nov & Dec & Annual \\
\hline 1 & 40.56 & 24.49 & 11.50 & 225 & 66 & 53 & 54 & 43 & 44 & 39 & 24 & 16 & 30 & 54 & 70 & 78 & 571 \\
\hline 2 & 40.67 & 22.89 & 17.88 & 321 & 45 & 39 & 44 & 38 & 50 & 38 & 29 & 23 & 29 & 46 & 59 & 56 & 494 \\
\hline 3 & 40.69 & 22.95 & 6.06 & 922 & 63 & 53 & 58 & 53 & 62 & 50 & 37 & 30 & 36 & 59 & 74 & 72 & 647 \\
\hline 4 & 40.31 & 21.45 & 3.23 & 946 & 75 & 63 & 65 & 63 & 68 & 44 & 37 & 33 & 44 & 80 & 91 & 85 & 749 \\
\hline 5 & 38.15 & 23.91 & 9.45 & 209 & 76 & 60 & 57 & 32 & 23 & 13 & 7 & 7 & 18 & 56 & 67 & 87 & 501 \\
\hline 6 & 39.50 & 21.64 & 2.70 & 924 & 99 & 83 & 77 & 68 & 62 & 43 & 31 & 25 & 43 & 88 & 101 & 114 & 835 \\
\hline 7 & 39.39 & 21.45 & 4.98 & 1319 & 117 & 96 & 88 & 75 & 66 & 45 & 34 & 30 & 47 & 95 & 120 & 130 & 942 \\
\hline 8 & 38.98 & 21.34 & 4.37 & 588 & 126 & 112 & 88 & 68 & 52 & 34 & 21 & 18 & 46 & 104 & 134 & 151 & 955 \\
\hline 9 & 40.43 & 21.98 & 0.16 & 1979 & 97 & 78 & 85 & 76 & 78 & 59 & 46 & 43 & 44 & 74 & 99 & 101 & 879 \\
\hline 10 & 39.17 & 20.79 & 3.32 & 447 & 140 & 123 & 94 & 70 & 52 & 29 & 19 & 20 & 55 & 119 & 160 & 169 & 1048 \\
\hline 11 & 39.68 & 20.50 & 1.05 & 506 & 157 & 141 & 105 & 81 & 62 & 33 & 22 & 26 & 65 & 128 & 183 & 189 & 1192 \\
\hline 12 & 39.74 & 20.21 & 0.36 & 367 & 170 & 156 & 112 & 82 & 58 & 27 & 18 & 25 & 71 & 138 & 202 & 209 & 1268 \\
\hline 13 & 39.49 & 20.17 & 0.83 & 159 & 150 & 138 & 98 & 70 & 47 & 19 & 12 & 19 & 69 & 135 & 188 & 186 & 1131 \\
\hline 14 & 38.76 & 22.62 & 7.09 & 403 & 89 & 75 & 68 & 52 & 41 & 31 & 17 & 13 & 30 & 73 & 78 & 108 & 674 \\
\hline 15 & 39.01 & 26.16 & 1.45 & 219 & 116 & 92 & 67 & 40 & 26 & 12 & 6 & 5 & 16 & 37 & 85 & 130 & 632 \\
\hline 16 & 37.57 & 26.13 & 0.91 & 366 & 132 & 98 & 75 & 36 & 21 & 8 & 4 & 2 & 13 & 46 & 81 & 138 & 656 \\
\hline 17 & 37.66 & 22.41 & 4.97 & 564 & 114 & 91 & 75 & 53 & 34 & 20 & 12 & 10 & 28 & 81 & 111 & 135 & 763 \\
\hline 18 & 37.68 & 22.13 & 3.87 & 1021 & 134 & 105 & 87 & 62 & 41 & 26 & 17 & 15 & 33 & 90 & 125 & 152 & 886 \\
\hline 19 & 37.58 & 21.71 & 5.23 & 248 & 122 & 96 & 75 & 50 & 28 & 12 & 7 & 8 & 32 & 98 & 133 & 150 & 813 \\
\hline 20 & 38.08 & 20.66 & 0.81 & 250 & 149 & 111 & 90 & 53 & 29 & 11 & 8 & 11 & 44 & 129 & 160 & 184 & 980 \\
\hline 21 & 36.85 & 26.99 & 0.99 & 282 & 168 & 108 & 82 & 35 & 22 & 4 & 1 & 1 & 13 & 53 & 92 & 162 & 742 \\
\hline 22 & 37.30 & 22.24 & 0.22 & 1633 & 154 & 116 & 101 & 68 & 45 & 27 & 19 & 17 & 33 & 92 & 129 & 163 & 965 \\
\hline 23 & 36.19 & 23.97 & 3.08 & 212 & 111 & 77 & 68 & 34 & 17 & 5 & 3 & 3 & 16 & 68 & 87 & 114 & 602 \\
\hline 24 & 36.20 & 27.94 & 1.08 & 216 & 216 & 101 & 94 & 29 & 23 & 3 & 2 & 1 & 13 & 69 & 121 & 207 & 877 \\
\hline 25 & 35.23 & 24.79 & 1.91 & 379 & 149 & 103 & 89 & 37 & 18 & 6 & 2 & 2 & 15 & 78 & 88 & 135 & 723 \\
\hline 26 & 35.24 & 24.69 & 1.24 & 541 & 176 & 125 & 109 & 43 & 22 & 9 & 4 & 2 & 18 & 92 & 98 & 156 & 854 \\
\hline 27 & 35.24 & 24.64 & 1.24 & 1003 & 200 & 139 & 125 & 51 & 28 & 13 & 6 & 4 & 20 & 98 & 108 & 175 & 968 \\
\hline \multicolumn{5}{|c|}{ Total Greece } & 94 & 75 & 68 & 49 & 43 & 29 & 20 & 17 & 32 & 72 & 92 & 108 & 699 \\
\hline
\end{tabular}

\section{Conclusions}

Cross correlation and principal components quantified the spatio-temporal patterns of precipitation revealing seasonal, latitudinal, longitudinal and elevation dependencies. The most significant findings were that a) the absolute correlations of precipitation versus elevation and longitude are minimized during the winter period, b) the latitude dependency of precipitation presents a seasonal shift where winter precipitation tends to be higher in northern Greece while summer precipitation tends to be higher in southern Greece and c) the first two principal components account for the $92.8 \%$ of variance in the spatiotemporal variability of precipitation in Greece

Cluster analysis segmented the terrain to 27 regions with distinct seasonal variability of precipitation, while the clusters which cover the majority of irrigated agricultural land (approximately 39\% of Greece) present the lowest values of annual precipitation $\left(<600 \mathrm{~mm} \mathrm{year}^{-1}\right)$.

The terrain segmentation according to the mean monthly values of $P$ for a 50 year period is a valuable tool for supporting environmental-agricultural decision support and risk assessment related to water resources 
management. Future attempts may also focus on the use of cluster analysis to climate change studies such as a) to assess the monthly precipitation changes within each cluster by integrating monthly $P$ data sets of the fore-coming years or to $b$ ) to use the data sets of the fore-coming years in order to recompute clusters in an attempt to evaluate any trends in the centroid change between two periods.

\section{Supplementary Material}

The supplementary material includes a polygon shapefile projected in WGS84 ellipsoid with the 27 clusters of Table 4. Each polygon contains the identity cluster number of $P$ from Table 4 . The file can be downloaded by the following source:

https://www.researchgate.net/publication/263660546

\section{References}

Bartzokas A., Lolis C.J. and Metaxas D.A. (2003), A study of the intra-annual variation and the spatial distribution of precipitation amount and duration over Greece on 10 day basis, International Journal of Climatology, 23, 207-222.

Demertzi K.A., Papamichail D.M., Georgiou P.E., Karamouzis D.N. and Aschonitis V.G. (2014), Assessment of rural and highly seasonal tourist activity plus drought effects on reservoir operation in a semi-arid region of Greece using the WEAP model, Water International, 39, 23-34.

Eastman J.R. and Fulk M. (1993), Long sequence time series evaluation using standardized principal components, Photogrammetric Engineering \& Remote Sensing, 59, 1307-1312.

Feidas H., Karagiannidis A., Keppas S., Vaitis M., Kontos T., Zanis P., Melas D. and Anadranistakis E. (2014), Modeling and mapping temperature and precipitation climate data in Greece using topographical and geographical parameters, Theoretical and Applied Climatology, (in press), doi:10.1007/s00704-013-1052-4.

Fotiadi A.K., Metaxas D.A. and Bartzokas A. (1999), A statistical study of precipitation in NW Greece, International Journal of Climatology, 19, 1221-1232.

Hijmans R.J., Cameron S.E., Parra J.L., Jones P.G. and Jarvis A. (2005), Very high resolution interpolated climate surfaces for global land areas, International Journal of Climatology, 25, 1965-1978.

Kaffas K. and Hrissanthou V. (2014), Application of a continuous rainfall-runoff model to the basin of Kosynthos river using the hydrologic software HEC-HMS, Global Nest Journal, 16, 188-203.

Loukas A., Vasiliades L., Dalezios N.R. and Domenikiotis C. (2001), Rainfal-frequency mapping for Greece, Physics and Chemistry of the Earth Part. B, 26, 669-674.

Maaten L. and Hinton G. (2008), Visualizing High-Dimensional Data Using t-SNE, Journal of Machine Learning Research, 9, 2579-2605.

Mather P.M. (2004), Computer processing of remotely-sensed images ( $3^{\text {rd }}$ edition), New York: John Wiley and Sons, $442 \mathrm{p}$.

Maeda E. and Hurskainen P. (2014), Spatiotemporal characterization of land surface temperature in Mount Kilimanjaro using satellite data, Theoretical and Applied Climatology, (in press), doi: 10.1007/s00704-013-1082-y

Miliaresis G. (2009), Regional thermal and terrain modeling of the Afar Depression from multi-temporal night LST data, International Journal of Remote Sensing, 30, 2429-2446.

Miliaresis G. and Partsinevelos P. (2010), Terrain Segmentation of Egypt from Multi-temporal Night LST Imagery and Elevation Data, Remote Sensing, 2, 2083-2096.

Miliaresis G. and Tsatsaris A. (2010), Thermal terrain modeling of spatial objects, a tool for environmental and climatic change assessment, Environmental Monitoring \& Assessment, 164, 561-572.

Miliaresis G. (2013), Thermal_anomaly mapping from night MODIS imagery of USA, a tool for environmental assessment. Environmental Monitoring \& Assessment, 185, 1601-1612. 
Miliaresis G. (2014), Spatiotemporal patterns of land surface temperature of Antarctica from MODIS Monthly LST data (MYD11C3), Journal of Spatial Sciences, 59, 157-166.

McMahon T.A., Peel M.C., Pegram G.G.S. and Smith I.N. (2011), A simple methodology for estimating mean and variability of annual runoff and reservoir yield under present and future climates, Journal of Hydrometeorology, 12, 135-146.

Metaxas D.A., Philandras C.M., Nastos P.T. and Repapis C.C. (1999), Variability of precipitation pattern in Greece during the year, Fresenius Environmental Bulletin, 8, 1-6.

Nastos P.T. and Zerefos C.S. (2010), Cyclic modes of the intra-annual variability of precipitation in Greece, Advances in Geosciences, 25, 45-50.

Oikonomou C., Flocas H.A., Hatzaki M., Asimakopoulos D.N. and Giannakopoulos C. (2008), Future changes in the occurrence of extreme precipitation events in Eastern Mediterranean, Global Nest Journal, 10, $255-262$.

Papamichail D.M. and Metaxa I.G. (1996), Geostatistical analysis of spatial variability of rainfall and optimal design of a rain gauge network, Water Resources Management, 10, 107-127.

Sheffield J., Goteti G. and Wood E.F. (2006), Development of a 50-yr high-resolution global dataset of meteorological forcings for land surface modeling, Journal of Climate, 19, 3088-3111.

Siljestrom P.A., Moreno A., Vikgren G. and Caceres L.M. (1997), The application of selective principal components analysis to a Thematic Mapper image for the recognition of geomorphologic features configuration, International Journal of Remote Sensing, 18, 3843-3852.

Stathis D. and Myronidis D. (2009), Principal component analysis of precipitation in Thessaly region (central Greece), Global Nest Journal, 11, 467-476.

Stathis D. and Mavromatis T. (2009), Characteristics of precipitation in Thessaloniki area, North Greece, Fresenius Environmental Bulletin, 18, 1270-1275.

Thenkabail P.S., Knox J.W., Ozdogan M., Gumma M.K., Congalton R.G., Wu Z., Milesi C., Finkral A., Marshall M., Mariotto I., You S., Giri C.P. and Nagler P.L. (2012), Assessing future risks to agricultural productivity, water resources and food security-how can remote sensing help?, Photogrammetric Engineering \& Remote Sensing, 78, 773-782. 